Ola P. Rosaeg MB BCh BAO FRCPC, Valerie Suderman MD, Ralph W. Yarnell MD FRCPC

\title{
Early respiratory depression during Caesarean section following epidural meperidine
}

\begin{abstract}
A case of respiratory depression which occurred following administration of epidural meperidine during Caesarean section is described. Epidural meperidine, $75 \mathrm{mg}\left(10 \mathrm{mg} \cdot \mathrm{ml}^{-1}\right)$ was given after delivery of the infant to provide postoperative analgesia. Oxygen desaturation $\left(\mathrm{SaO}_{2} 90 \%\right)$ and a decrease in respiratory rate $\left(4 \cdot \mathrm{min}^{-1}\right)$ were noted $30 \mathrm{~min}$ after epidural meperidine was administered. Naloxone. $0.1 \mathrm{mg}$, was given iv which resulted in prompt improvement in both respiratory rate and oxygen saturation. Vascular absorption of meperidine from the epidural venous plexus is the most probable explanation for this case of early respiratory depression. We recommend a maximum bolus dose of $50 \mathrm{mg}$ of epidural meperidine for pain management after Caesarean section. It is also important to monitor oxygen saturation continuously during the intruoperative period, and to monitor the patient closely in the recovery room for at least one hour for evidence of respiratory depression.
\end{abstract}

Un cas de dépression respiratoire qui est survenu après administration épidurale de mépéridine durant une césarienne est décrit. Du mépéridine par voie épidurale $75 \mathrm{mg}\left(10 \mathrm{mg} \cdot \mathrm{ml}^{-1}\right)$ est administré après l'accouchement afin de fournir une analgésie postopératoire. La désaturation en oxygène $\left(\mathrm{SaO}_{2} 90 \%\right)$ et la diminution de la fréquence respiratoire $\left(4 \cdot \mathrm{min}^{-1}\right)$ furent

\section{Key words}

ANAESTHESIA: obstetrical;

ANAESTHETIC TECHNIQUES: epidural;

ANALGESIA: epidural;

ANALGESICS: meperidine;

COMPLICATIONS: respiratory.

From the Ottawa Civic Hospital, Department of Anaesthesia, University of Ottawa.

Address correspondence to: Dr. O.P. Rosaeg, Department of Anaesthesia C3, Ottawa Civic Hospital, 1053 Carling Ave., Ottawa, Ontario K1Y 4E9.

Accepted for publication 29th August, 1991. notées 30 minutes après administration épidurale de mépéridine. Du naloxone $0,1 \mathrm{mg}$ fut administré par voie intraveineuse, ce qui a amené une amélioration de temps de la fréquence respiratoire et de la saturation en oxygène. L'absorption vasculaire de mépéridine à travers le plexus veineux épidural est l'explication la plus probable de ce cas de dépression respiratoire précoce. On recommande une dose maximale de bolus de $50 \mathrm{mg}$ de mépéridine épidurale pour le soulagement de la douleur après césarienne. Il est aussi important de surveiller continuellement la saturation en oxygène durant la période peropératoire et de surveiller le patient érroitement dans la salle de réveil pour au moins une heure afin de mettre en évidence une dépression respiratoire.

Epidural opioids have gained popularity as effective analgesic agents for pain management following Caesarean section. However, the administration of epidural morphine with its low lipophilicity has been associated with several side-effects: late respiratory depression, pruritus, nausea and vomiting, urinary retention and recrudecence of peri-oral herpes simplex infection. 'The incidence of late respiratory depression is low, but requires close nursing supervision and monitoring of respiratory rate for at least $12 \mathrm{hr}$ after the administration of epidural morphine. ${ }^{2,3}$ Therefore, several investigators have assessed the efficacy of more lipophilic drugs such as the phenylpiperidine derivatives meperidine and fentanyl. ${ }^{4-7}$ Although these opioid analgesics have a shorter duration of action, it was considered that their lipophilic structure would result in a smaller quantity of drug being available for rostral spread in the CSF. Hence, late respiratory compromise following epidural administration of meperidine or fentanyl should occur less frequently.

We describe a case of early respiratory depression after administration of epidural meperidine. This occured in a non-premedicated woman $\mathbf{3 0}$ min after delivery by Caesarean section and required treatment with intravenous naloxone. 


\section{Case report}

A 34-yr-old, $173 \mathrm{~cm}, 95 \mathrm{~kg}$, gravida 3, para 2 woman presented at $38 \mathrm{wk}$ gestation for repeat Caesarean section. She had previously had an uneventful general anaesthetic for placenta praevia. She was a healthy parturient although at $20 \mathrm{wk}$ gestation her obstetrician had referred her to a cardiologist due to dyspnoea. The cardiologist failed to find any pathology related to the cardiovascular system. The complaint subsided as pregnancy progressed and during the third trimester she was entirely symptom-free. A thorough preoperative examination of the cardiovascular and respiratory systems was normal. She received no premedication apart from $30 \mathrm{ml}$ sodium citrate po. An epidural catheter was inserted uneventfully at the $\mathrm{L}_{2-3}$ interspace with the patient in the sitting position using a \#16 g Tuohy needle and loss of resistance to air. The patient was positioned supine with left uterine displacement. Monitors used included an automatic blood pressure cuff, ECG, and an oximeter using a finger probe. Oxygen was administered via a clear face mask at $6 \mathrm{~L} \cdot \mathrm{min}^{-1}$. A test dose of $3 \mathrm{ml}$ lidocaine $\mathrm{CO}_{2}$ with 1:200,000 epinephrine was given at 0920 . No increase in heart rate or sensory or motor block were noted. At $09455 \mathrm{ml}$ lidocaine $\mathrm{CO}_{2}$ with 1:200,000 epinephrine was given followed by a further $12 \mathrm{ml}$ of the same local anaesthetic given in three increments at three-minute intervals. This achieved a sensory level of $T_{6}$ to pin prick and surgery commenced at 1005. A healthy infant was delivered at 1023. Prior to delivery, maternal oxygen saturation $\left(\mathrm{SaO}_{2}\right)$ was continuously $100 \%$.

Following the delivery of the baby the oxygen mask was removed from the mother's face to allow interaction between mother and baby. At 1024, $75 \mathrm{mg}$ epidural meperidine was administered $\left(10 \mathrm{mg} \cdot \mathrm{ml}^{-1}\right)$ to provide postoperative analgesia following regression of the local anaesthetic block. The initial $\mathrm{SaO}_{2}$ after the delivery breathing room air was $99 \%$. Approximately ten minutes following delivery $1.0 \mathrm{mg}$ of droperidol was given iv to prevent nausea after meperidine. When the newborn and father left the operating room at 1045 , the patient was noted to be somewhat drowsy; her eyes were closed but she responded immediately to verbal stimulation. The $\mathrm{SaO}_{2}$ was noted to have decreased and at 1050 a reading of $94 \%$ was recorded. Two minutes later a $\mathrm{SaO}_{2}$ of $90 \%$ was noted which improved to $97 \%$ when the patient was encouraged to take some deep breaths. During the following two minutes the patient was left alone without physical or verbal stimulation by the anaesthetist. Her respiratory rate was now only $4 \mathrm{~min}^{-1}$ and the $\mathrm{SaO}_{2}$ decreased again to $91 \%$. The systolic blood pressure was $105 \mathrm{mmHg}$ at this time, which was identical to the preoperative systolic blood pressure, while her pulse rate was 95 $\mathrm{min}^{-1}$. At $10540.1 \mathrm{mg}$ naloxone was administered $i v$, the respiratory rate improved to $10-14 \mathrm{~min}^{-1}$ and the $\mathrm{SaO}_{2}$ was subsequently in the range of $95-97 \%$. At 1100 she was transferred to the recovery room. She remained somewhat somnolent for the following $45 \mathrm{~min}$, but the respiratory rate was at all times $>10 \mathrm{~min}^{-1}$ and the $\mathrm{SaO}_{2}$, which was monitored continuously, ranged between $95 \%$ and $98 \%$. At 1145 the upper sensory level of block was $T_{12}$ and she was alert and pain-free. She remained comfortable until 1400, when she complained of incisional pain. Meperidine $75 \mathrm{mg}$ im was given with good effect, and she was discharged to the post-partum ward at 1415. The remaining stay in the hospital was uneventful and she was discharged on the fifth post-partum day.

\section{Discussion}

The discovery that intrathecal opioids blocked transmission of pain at the spinal cord level prompted the use of epidural meperidine to treat cancer pain and postoperative pain after major abdominal surgery. Cousins et al. ${ }^{8}$ used $100 \mathrm{mg}$ of meperidine $\left(10 \mathrm{mg} \cdot \mathrm{ml}^{-1}\right)$ and found that complete pain relief occurred within 12-20 min and was followed by a mean duration of analgesia of six hours. However, soon after this initial report, Scott and $\mathrm{McClure}^{9}$ described two cases of severe respiratory depression, requiring treatment with $i v$ naloxone, occurring $30 \mathrm{~min}$ after epidural administration of 50 and $100 \mathrm{mg}$ of meperidine. In both instances im diamorphine had been administered preoperatively.

Whereas respiratory depression following epidural morphine is a recognized, albeit rare, potential complication in the post-partum patient, ${ }^{1}$ the relative safety of epidural meperidine administration for postoperative analgesia has been determined in several studies. ${ }^{2,45,10}$ Gustafsson, in a retrospective survey in Sweden, found no instance of respiratory depression following the use of epidural meperidine. ${ }^{10}$ Brownridge, in his series of more than 7000 patients who had received epidural meperidine, did not find one case of respiratory depression following epidural meperidine. ${ }^{4}$ However, one patient suffered respiratory arrest requiring treatment with iv naloxone and airway support following inadvertent subarachnoid injection of $50 \mathrm{mg}$ meperidine. ${ }^{11}$ Paech $^{7}$ described one patient who suffered a transient descrease in respiratory rate from $16 \mathrm{~min}^{-1}$ to $8 \mathrm{~min}^{-1}$, five min after administration of $50 \mathrm{mg}$ epidural meperidine. This episode lasted one hour and $i v$ naloxone was not given.

The amount of local anaesthetic ( $20 \mathrm{ml}$ lidocaine $\mathrm{CO}_{2}$ with 1:200,000 epinephrine) required to achieve a $T_{6}$ sensory blockade in our patient, and the time course for progression and regression of the sensory and motor block favour an epidural location of the catheter. If the catheter had been inserted inadvertently into either the subdural or subarachnoid space a more profound respiratory compro- 
mise might be expected as well as a more extensive local anaesthetic block. The patient received no premedication and did not receive other parenteral sedatives or narcotics either before or after epidural meperidine administration, except a small $(1.0 \mathrm{mg})$ dose of $i v$ droperidol ten minutes after delivery of the infant. We routinely give small iv boluses of droperidol $(0.5-1.0 \mathrm{mg})$ to these patients to prevent or treat intraoperative nausea due to opioid analgesics. We have not encountered any complications associated with its use. However, Cohen et al. ${ }^{12}$ described a patient with early respiratory depression after epidural hydromorphone and $1.25 \mathrm{mg}$ of $i v$ droperidol. This patient did not respond to a large $(3.2 \mathrm{mg})$ intravenous dose of naloxone, rather improvement in her condition only occurred following iv administration of $1.0 \mathrm{mg}$ physostigmine. In our patient respiratory depression (respiratory rate $4 \mathrm{~min}^{-1}$, oxygen saturation $90 \%$ ) occurred $30 \mathrm{~min}$ after injection of epidural meperidine. Prompt improvement in both respiratory rate and oxygen saturation occurred following only $0.1 \mathrm{mg}$ iv naloxone; therefore, the respiratory depression observed was associated with the administration of epidural meperidine.

Since Cousins' early report on the effectiveness of epidural meperidine the CSF and plasma pharmacokinetic behaviour of meperidine after epidural injection has been clarified, to predict the risk of respiratory depression. Sjostrom et al. ${ }^{13}$ showed that meperidine rapidly crossed the dura to gain access to CSF; maximal CSF concentrations were seen 15-30 min after injection of epidural meperidine. At the same time considerable absorption of meperidine occurred into the circulation from the epidural venous plexus. The maximum plasma concentration occurred only 10-15 min after epidural injection. These findings correlated well with earlier work by Glynn et al. ${ }^{14}$ who showed that plasma concentration $20 \mathrm{~min}$ after injection of $100 \mathrm{mg}$ of meperidine in non-pregnant patients could reach $200-700 \mathrm{ng} \cdot \mathrm{ml}^{-1}$. They concluded that these relatively high plasma meperidine concentrations would contribute to analgesia since a serum level of $400 \mathrm{ng} \cdot \mathrm{ml}^{-1}$ is generally associated with moderate analgesia following iv of meperidine. ${ }^{15,16}$ Gourlay et al. ${ }^{17}$ determined that meperidine appeared quickly in the CSF at the $\mathrm{C}_{7}-\mathrm{T}_{1}$ interspace following lumbar epidural injection. Peak CSF concentration at $C_{7}-T_{1}$ was achieved after 10-60 min. Maximum serum concentration of meperidine was achieved after 21 (mean) min.

In reviewing pharmacokinetic data of epidural meperidine, Cousins ${ }^{18}$ suggested that if meperidine is to cause respiratory depression this was likely to occur within 60 min after injection due to drug migration in the CSF towards the brain as well as absorption of meperidine into the circulation. Recently, Maurette et al. ${ }^{19}$ have found that ventricular and plasma meperidine concentrations fol- lowed a similar time course and that the time to maximal concentration ( $\mathrm{T} \max$ ) in CSF occurred later than plasma T max. Correlating this data with earlier findings showing the time interval of CSF bulk flow from the lumber area to cisterna magna to be $3-6 \mathrm{hr},{ }^{20.21}$ they attributed the high levels of meperidine in ventricular CSF within the first hour following lumbar administration to rapid and extensive vascular absorption of meperidine. This would result in diffusion of meperidine from plasma into the CSF through the choroid plexus.

The pharmacokinetics of meperidine is different in the pregnant from the non-pregnant woman. Husemeyer $e t$ $a l^{22}$ showed that the mean plasma meperidine concentration exceeded $600 \mathrm{ng} \cdot \mathrm{ml}^{-1}$ ten minutes after injection of $100 \mathrm{mg}$ of meperidine into the lumber epidural space in labouring women. This was higher $(P<0.05)$ than plasma levels achieved in the non-pregnant woman following an identical dose of epidural meperidine. Therefore, vascular absorption of meperidine with its lipophilic molecular characteristics (Octanol:water partition coefficient being 39 vs 1.4 for morphine) is more extensive in the pregnant woman than the non-pregnant woman. Severe respiratory depression has been reported in patients with plasma meperidine levels exceeding $600 \mathrm{ng} \cdot \mathrm{ml}^{-1}$ following parenteral administration of meperidine. ${ }^{16.23}$ Taking into consideration the findings of Maurette et al. ${ }^{19}$ and Husemeyer et al., ${ }^{22}$ the probable aetiology of the early respiratory depression in our patient was rapid and extensive absorption of meperidine into the circulation.

The principal plasma carrier protein for both lidocaine and meperidine is alpha $a_{1}$ acidglycoprotein $\left(\alpha_{1}-A G P\right)$. The free fraction (unbound to plasma proteins) of meperidine is approximately 0.37 ; furthermore, a linear correlation exists between meperidine binding ratio (bound/free) and plasma $\alpha_{1}$-AGP concentration. ${ }^{24}$ It is, however, not clear whether the presence of lidocaine on $\alpha_{1}$-AGP binding sites would result in an altered binding ratio of meperidine following concomitant epidural administration of these two drugs.

Dose-response studies are required to determine the analgesic effect following various dosing regimens of epidural meperidine and Caesarean section. Until these data become available we recommend a maximum bolus dose of $50 \mathrm{mg}$ of epidural meperidine for post-partum analgesia following Caesarean delivery. Secondly, we recommend that patients be observed carefully during operation and that maternal oxygen saturation be monitored continuously during the intraoperative period. In view of the potential for respiratory depression within the first hour after injection of epidural meperidine, we recommend close supervision in the recovery room for at least one hour before discharge to the post-partum ward to detect undue sedation and decrease in respiratory function. 
In summary, we have described early respiratory depression in a patient which occurred during Caesarean section following epidural meperidine administration. A recent report by Brockway et al. ${ }^{25}$ described respiratory arrest in a patient undergoing Caesarean section after administration of epidural fentanyl. Therefore, it seems likely that the lipophilic phenlypiperidine derivatives can be associated with early respiratory compromise in susceptible opioid-naive post-partum women.

\section{References}

1 Fuller JG, McMorland GH, Douglas MJ, Palmer L. Epidural morphine for analgesia after Caesarean section: a report of 4880 patients. Can J Anaesth 1990; 37: 636-40.

2 Rawal N, Arner S, Gustafsson LL, Allvin R. Present state of extradural and intrathecal opioid analgesia in Sweden. Br J Anaesth 1987; 59: 791-99.

3 Writer WDR. Epidural morphine for post-Caesarean analgesia. Can J Anaesth 1990; 37: 608-9.

4 Brownridge $P$. Epidural and intrathecal opiates for postoperative pain relief. Anaesthesia $1983 ; 38: 74-5$.

5 Brownridge $P$, Frewin $D B$. A comparative study of techniques of postoperative analgesia following Caesarean section and lower abdominal surgery. Anaesth Intensive Care 1985; 13: 123-30.

6 Naulty JS, Datta S, Ostheimer GW, Johnson MD, Burger GA. Epidural fentanyl for postcesarean delivery pain management. Anesthesiology 1985; 63: 694-8.

7 Paech MJ. Epidural pethidine or fentanyl during Caesarean section: a double-blind comparison. Anaesth Intensive Care 1989; 17: 157-65.

8 Cousins MJ, Mather LE, Glynn CJ, Wilson PR, Graham $J R$. Selective spinal analgesia. Lancet 1979; 1: 1141-2.

9 Scott $D B, M c C l u r e ~ J$. Selective epidural analgesia. Lancet 1979; 1: 1410-1.

10 Gustafsson $L L$, Schildt B, Jacobsen $K$. Adverse effects of extradural and intrathecal opiates: reports of a nationwide survey in Sweden. Br J Anaesth 1982; 54: 479-86.

11 Brownridge P, Wrobel J, Watt-Smith J. Respiratory depression following accidental subarachnoid pethidine. Anaesth Intensive Care 1983; 11: 237-40.

12 Cohen SE, Rothblatt A.J, Albright GA. Early respiratory depression with epidural narcotic and intravenous droperidol. Anesthesiology 1983; 59: 559-60.

13 Sjöström S, Hartvig P, Persson P, Tamsen A. Pharmacokinetics of epidural morphine and meperidine in humans. Anesthesiology 1987; 67: 877-88.

14 Glynn CJ, Mather LE, Cousins MJ, Graham JR, Wilson $P R$. Peridural meperidine in humans: analgetic response, pharmacokinetics, and transmission into CSF. Anesthesiology $1981 ; 55: 520-6$.
15 Kanto J. Obstetric analgesia: clinical pharmacokinetic considerations. Clin Pharmacokinet 1986; 11: 283-98.

16 Mather LE, Meffin PJ. Clinical pharmacokinetics of pethidine. Clin Pharmacokinet 1978; 3: 352-68.

17 Gourlay Gk, Cherry DA, Plummer JL, Armstrong PJ, Cousins $M J$. The influence of drug polarity in the absorption of opioid drugs into CSF and subsequent cephalad migration following lumbar epidural administration: application to morphine and pethidine. Pain 1987; 31 : 297-305.

18 Cousins $M J$. Comparative pharmacokinetics of spinal opioids in humans: a step toward determination of relative safety (editorial). Anesthesiology 1987; 67: 875-6.

19 Maurette P. Tauzin-Fin P. Vincon G, Brachet-Lierman A. Arterial and ventricular CSF pharmacokinetics after intrathecal meperidine in humans. Anesthesiology 1989; 70: $961-6$.

20 Dichiro $G$. Movement of the cerebrospinal fluid in human beings. Nature 1964; 204: 290-1.

21 Dichiro G. Observations on the circulation of the cerebrospinal fluid. Acta Radiol 1966; 5: 988-1002.

22 Husemeyer RP, Cummings AJ, Rosankiewicz JR, Davenport $H T$. A study of pethidine kinetics and analgesia in women in labour following intravenous, intramuscular and epidural administration. Br J Clin Pharmacol 1982; 13: $171-6$.

23 Rigg JRA, Ilsley AH, Vedig AE. Relationship of ventilatory depression to steady-state blood pethidine concentrations. Br J Anaesth 1981; 53: 613-9.

24 Nation RL. Meperidine binding in maternal and fetal plasma. Clin Pharmacol Ther 1981; 29: 472-9.

25 Brockway MS, Noble DW, Sharwood-Smith GH, McClure $J H$. Profound respiratory depression after extradural fentanyl. Br J Anaesth 1990; 64: 243-5. 